\title{
Aquaculture Research Issues, Opportunities and Current Priorities in Nigeria
}

\author{
Ugoala, Emeka \\ Fisheries Products' Development Programme, National Institute For Freshwater Fisheries Research, P.M. B. \\ 6006, New Bussa 913003, Niger State, Nigeria
}

\begin{abstract}
Fisheries and aquaculture continue to be a very important source of food, employment and revenue in many countries. The growth of commercial aquaculture has brought with it more intensified methods of production. Against a continuing background of diminishing and over-exploited aquatic resources, aquaculture has been widely held up as panacea to the problem of providing a growing world population with everincreasing amounts of fish for consumption. While innovative aquaculture involves the applications of new and more effective ways or solutions for aquaculture management, there may be interventions related to breeding and farming techniques, aquatic environment management, disease control or animal health monitoring, nutrition and feed management of the cultured organisms, genetics and biotechnological tools which directly or indirectly play roles in improvement of aquaculture production in an environment-friendly and sustainable manner. Aquatic Resource and their sustainable management for biodiversity conservation constitute a multifacetted complex system. The challenges are manifold.
\end{abstract}

Keywords: Management; Pollution; Environment

\section{Introduction}

Aquaculture is a technology driven industry which relies heavily on research to develop new species and the appropriate technology for commercial production. At present, aquaculture in Nigeria is dominated by finfish and exciting new industry initiatives are presently underway that are exploring the culture of indigenous shellfish farming. However, despite these enterprises there is considerable scope for the sector to diversify further. In fact, expanding the species base can be regarded as a prerequisite for the development of a globally competitive industry as well as for bringing appropriate technology to the small-scale, community-based operation.

Nigeria is by far the most important state for the direct human consumption of fish, owing to a mixture of large population and relatively high per capita consumption levels. Its costal fisheries resources are depleted or close to depletion, so little growth could be expected from capture fisheries. Therefore aquaculture production must increase to meet the further demands of the population. The present study is intended to highlight some directions that could help arrive at more widespread fisheries prosperity. There is now burgeoning knowledge, wide range of tool and scientific and technical approaches including insights into social, economic and cultural conditions.

\section{Post Harvest Technologies}

\section{Current Research Activities}

Presently, the mechanization level of fish processing is low which results from the overall limited production, seasonal availability of fish, and poor information dissemination of the available improved technology to processors, and lack of inexpensive technologies to enable maximal use of raw material and thus contribute to increase economic profitability. The problem of high incidence of losses has been recognized as a major impediment to realization of the Nigeria government goal of increasing the contribution of the fish industry sector to overall national economy.

High post-harvest losses, arising largely from limited preservation capacity, are a major factor constraining fish and nutrition security. Ineffective or inappropriate processing technologies, careless harvesting and inefficient post-harvest handling practices, among others are factors responsible for high post-harvest losses. The capacity to preserve is directly related to the level of technological development and the slow progress in upgrading traditional processing and preservation techniques contributes to fish insecurity. Traditional technologies of fish processing and preservation date back thousands of years and form part of the culture of the people. It constitutes a vital body of indigenous knowledge handed down from parent to child over several generations. Unfortunately, this vital body of indigenous knowledge is often undervalued.

The fish industry in the region consists largely of indigenous small-scale (as small as one person) enterprises owned by indigenous operators. Unfortunately, rapid growth and development of small-scale fish industries is hampered by adoption of inefficient or inappropriate technologies, poor management, inadequate 
working capital, and limited access to banks and other financial institutions, high interest rates and low profit margins. One of the greatest challenges facing fish processors is the upgrading of the traditional technologies of food processing and preservation. In most cases, the traditional methods of fish processing and preservation remain at the empirical level. They are still rather crude, are not standardized, and are not based on sound scientific principles making them, in their present form, unsuitable to large-scale industrial production. The processes are often laborious and time consuming and invariably the quality of the products require substantial improvements. In upgrading these technologies, the Scientist or Technologist is faced with the challenge of modernizing the processes and equipment while still retaining the traditional attributes of the products crucial to consumer acceptance.

The rectangular ones are sometimes grouped together to larger units of three or more. To keep as much of the heat as is possible in the drying oven it is covered with a thin sheet of metal, usually flattened pieces of corrugated roofing material.

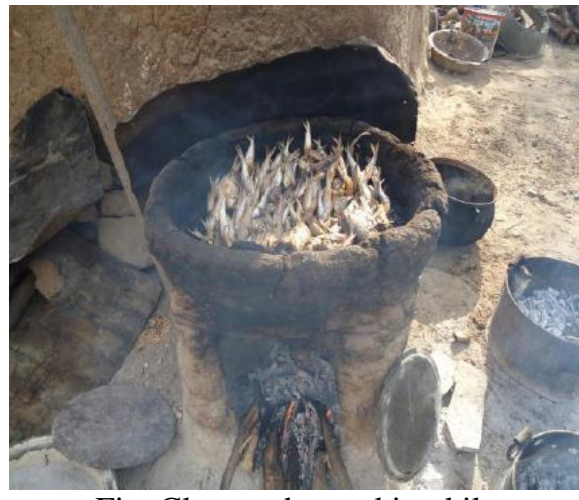

Fig. Clay made smoking kiln

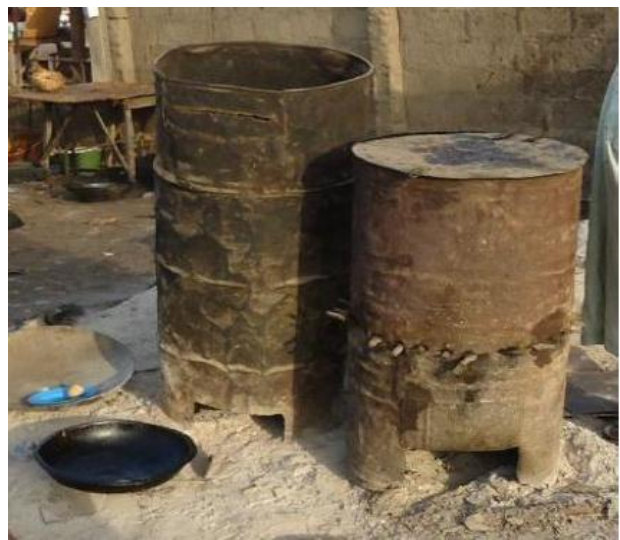

Fig. Drum made smoking kiln

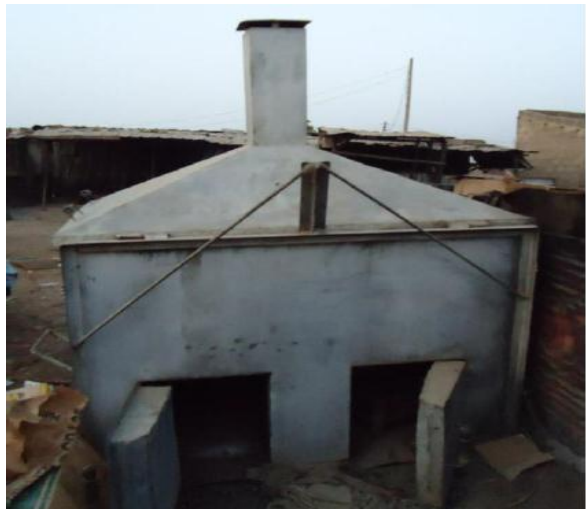

Fig. Fabricated smoking kiln with chimney

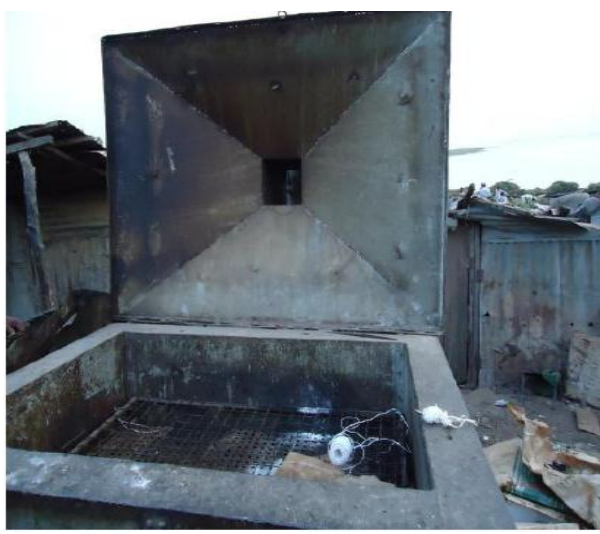

Fig. Inside view

The irregular shape of these, their battered appearance and the fact that mostly they were torn in various places makes the effectiveness of this method far less than what could be regarded as a possible maximum. The cover of the kiln, can, with a bit of fantasy, be regarded as a roof with a rather uncontrollable air outlet. The drying ovens in their present shape make it difficult to put more than one drying rack in the kiln, as is done for example in the Altona oven. It could be done by having an additional loose drying rack fitting into the kiln and kept at a distance from the underlying supporting rack by metal legs or even by a few bricks. 


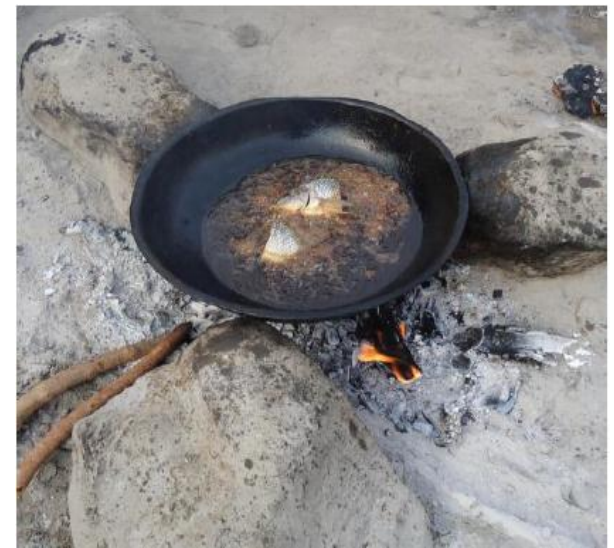

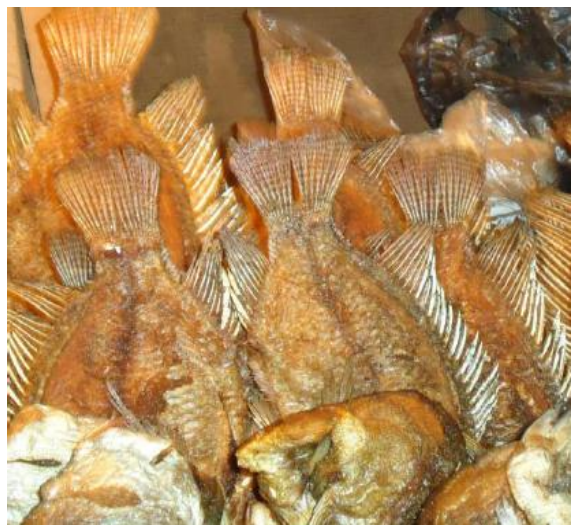

Fig. Fried fish

Fig. Fish frying

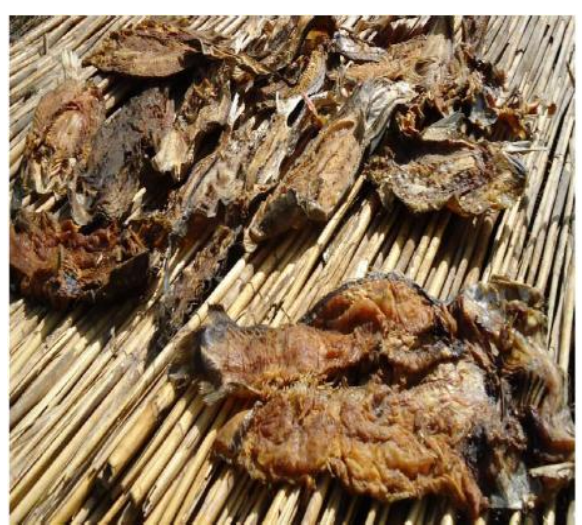

TRADITIONAL GEARS

Gill Net

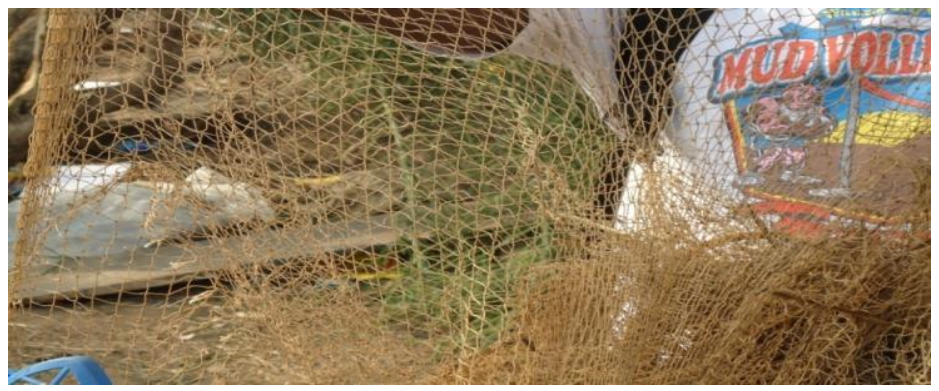

Figure: An inch mesh size gillnet

These are single walled nets with a mesh opening of such a size that the required fish can gill themselves in the netting. This is a passive gear, but fish can also be driven into the gill nets. The nets are used singly or in series. This is the most widely used fishing gear. They are vertical walls of netting normally set out in a straight line. Floats and sinkers are attached plastic ropes are used as head ropes and foot ropes. There is various mesh size of gill net used. The gill nets are directly purchase from the market or purchase as twine and making of net is done at home. The other materials such as footrope, head rope, float, sinker etc. are also purchased from the market.

\section{Cast Net}

These nets are conical shape nets. The lower edge is provided with footrope attaching a series of sinkers to it. This is a falling gear; here the fishing is done by direct quick movement of the gear to cover the fish. It is mainly operate in shallow water. Due to the sinker provided the gear sinks quickly in the form of an umbrella thus cover the fish.

\section{Malian Trap}




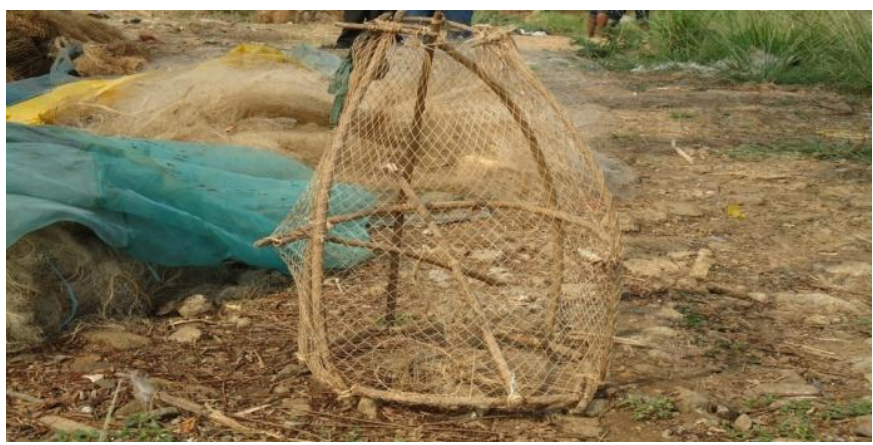

Figure : The Malian trap

These are implements in which the fish enters voluntarily but it hampered from coming out. Mostly in these traps a retarding device like gorges or funnels is provided to avoid the coming out of the fish. An entrance is provided at the middle of one side of the longitudinal portion where the fish to enter, but prevent to escape by fixing a comb like strips which are fitted at a rubber string which is of flexible commonly known as funnel. Once the fish is entered it is trapped inside. The material used for the construction of this gear is strips of small and finger size; this is tight by a synthetic yarn. This traps are set longitudinally by tightening to a floating weeds or by submerging $3 / 4$ portion to the gapes found at floating weeds. They are also operated in shallow water near the shore of channels either singly or even in series. The gear is used throughout the year

\section{Longline}

Longlines may be set stationary or towed through water or left drifting. They are bottom set with the help of weights, or left drifting with the help of floats. It is mainly operate in lakes. It consists of a main line and a branch line the main line is a nylon twine the length can be of any length according to the convenience. The branch line is fixed to this main line at an interval of 2 to 2.5 metres. The hooks are tight to this branch line by proper knot. The hook at the branch line is provided with bait. Float, sinkers are not used in this gear. The branch line touched to the ground in some cases. The main line is tied to the available weeds or fixed poles at several points. This gear operates in the lakes. One or two fishermen operate the line. If operation is done by two fishermen, one fisherman oars the canoe the other fisherman releases the line and tight at particular intervals to the pole or weeds. The difference in operation of long line in lake fishing to that of riverine fishing is that, in riverine fishing the line is lower at the bottom of the river in some cases weight are also fitted to this line. No float is used.

Hook and Line

Hook and line refers to fisheries that have a single or only a few hooks on a line.

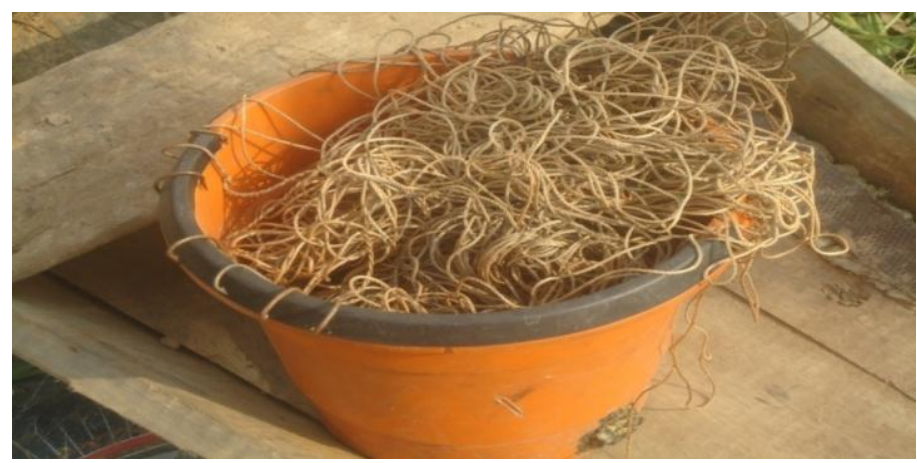

Figure : Hook and Line

\section{ASSOCIATED ECOLOGICAL IMPACTS OF FISHING GEAR}

The ecological impacts of fishing gear on habitat and the incidental catch of non-target species should play a significant role in fisheries management. Damage to aquatic habitats encourages steady decline or collapsed aquatic species. The consequences of commercial exploitation of fish on the reservoir seemed to have followed much the same pattern, as once-abundant species have proven no match for fishing pressure. The availability of fishing gears has contributed to increased fishing power and fishing pressure in the reservoir particularly under conditions of weak management of the reservoir. 
Table 1: Ecological Impacts of Fishing Gear

\begin{tabular}{|l|l|}
\hline GEAR & EFFECTS \\
\hline Gillnet & $\begin{array}{l}\text { Gillnets contact the seafloor, although the area impacted is assumed to be less than that of mobile gear such } \\
\text { as trawls and dredges. }\end{array}$ \\
\hline Longline & $\begin{array}{l}\text { Habitat damage from bottom longlines depends on the gear configuration including weights, number of } \\
\text { hooks and type of line as well as hauling speed and technique. Habitat damage is also dependent on bottom } \\
\text { type, with documentation of damage to corals and sponges. In one study, 4\% of corals along a transect had } \\
\text { been damaged by bottom longlines. }\end{array}$ \\
\hline Trap & $\begin{array}{l}\text { Habitat damage from pots and traps can depend on many factors: size, weight and material of the trap; } \\
\text { hauling speed and ocean conditions; depth of haul; number of traps set; and the substrate where the trap is } \\
\text { placed. When traps make contact with the seafloor, they cause benthic disturbance, especially during } \\
\text { hauling when they may be dragged over the seafloor. Fish traps are often larger and heavier than } \\
\text { invertebrate traps so can cause more damage than lighter gears such as inshore lobster pots. }\end{array}$ \\
\hline $\begin{array}{l}\text { Hook } \\
\text { Line }\end{array}$ & $\begin{array}{l}\text { Though suspended in the water, ground fish hook and line fisheries can come into contact with the seafloor, } \\
\text { snagging or entangling structures such as corals and sponges. Otherwise, associated habitat damage is low. }\end{array}$ \\
\hline
\end{tabular}

\section{FISHING CRAFTS}

Fishing craft is a carrier of floating plate form by which fishermen go to the fishing grounds along with equipment and back along with the catches to the shore.

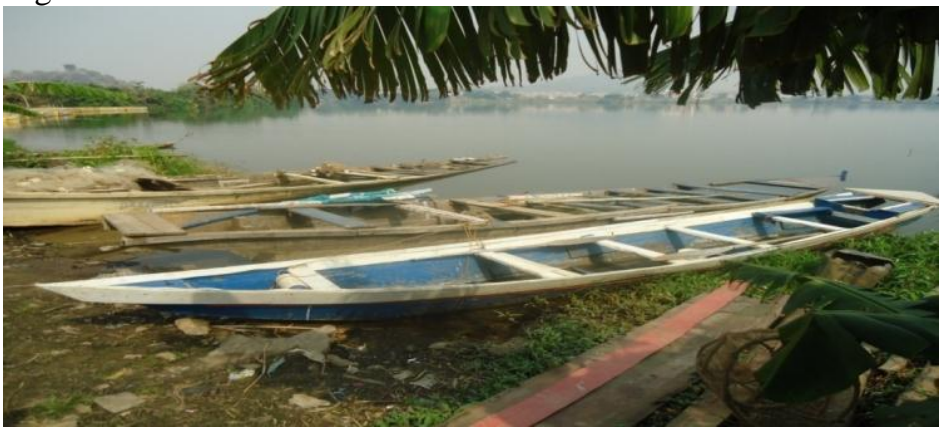

Figure : Varieties of undecked canoes on Jabi Reservoir

The fishing crafts found in streams, lakes, rivers are of small and medium size wooden canoes made by joining planks (un-decked). The plank build canoes are propelled using an oar.

The plank build canoes are made by joining the planks. The aft and stern portion of the plank build canoe is made separately by joining several pieces of wood. The main problem of the canoe is the leaking at the joints. Most of the plank builds canoes require repairing after $2 / 3$ years in operation. The thickness of the side wall varies from 1 inch to 1.5 inches, depending on the size of the canoe. The lower portion of the hull plank is thicker than the side plank. Usually the plank build canoes are made with slightly curving hull which makes the canoe easy for oaring. If the hull plank is less in thickness the canoe is unstable in operation.

The canoe manufactured here are not always treated with paints even in some cases the outer portion is not fully polished. When discussed, if there can be a change of material for the construction of canoe by fibre glass or any other suitable materials, the craftsmen were found totally unaware of any materials other than wood.

\section{FISH SEED PRODUCTION}

Inland aquaculture has relied on hatchery-produced seed which does not lead to overfishing of wild stocks. Overfishing has been reported in connection with tropical marine fish and shrimp culture, causing depletion of wild stocks (Beveridge and Phillips, 1990). The amount of seed available is not always enough, causing ponds to remain un-stocked, thus providing mosquitoes and snails with ideal habitats. This can increase the prevalence of schistosomiasis and malaria, as well as other mosquito-transmitted diseases such as filariasis.

Fish seed production is a specialised farming system practiced by skilled farmers only. An increasing number of hormones and growth promoters are used to change the sex, productive viability and growth of cultured organisms. It is capital intensive and time consuming. A fingerling production technique involves a series of breeding and feeding activities that can be grouped under the following successive operational stages:

\section{Induced spawning of eggs and milt using natural or synthetic gonadotropic hormones}

Sex differentiation. An acid $\left(\mathrm{H}_{2} \mathrm{SO}_{4}\right)$ environment can stimulate a significant increase of gametes in the gonads of female rainbow trout during oogenesis while in some fish, growth and maturation of late-generation oocytes is increased (Zelennikov, 1996). 
Induced gamete maturation and ovulation. Induced spawning is a major source of fish seed production for majority of fish species. Acetone-dried carp pituitary could be used to induce maturation and ovulation in the gravid brood fish. The spawning mat is made from synthetic fibres and twine.

Monoclonal antibodies (MAb) produced from lymphoid cells of immunised mice and immortalised by hybridisation with established myelome cells using polythene glycol as the substrate. MAb has made profound impression in diagnosis, stereotyping, and analysis of antigens in microbial pathogens, disease research and health management in medical and veterinary sciences.

\section{Fertilisation}

Milt extenders and preservatives. Storage of gonads or even embryos implied conservation of genetic resources of domesticated stocks, or as a tool in normal breeding for routine or special use. The knowledge gained from the study the internal environment of the milt of fish had led to the development of artificial seminal plasma (ASP). ASP constituents include $\mathrm{NaCl}, \mathrm{KCl}, \mathrm{CaCl}_{2}, \mathrm{MgCl}_{2}$, and $\mathrm{NaHCO}_{3}$ could be buffered with Tris (hydromethyi) methyl-aminopropanesulphonic acid (TAPS)- $\mathrm{NaOH}, \mathrm{NaHCO}_{3}-\mathrm{CO}_{2}$ or TAPS- $\mathrm{HCl}$ with dimethylsulphoxide (DMSO) as a cryoprotectant. ASP storage of milt would minimise the number of males to be sacrificed during artificial insemination since it can reversibly activate the sperm.

The cryoprotective diluents include ethylene glycol, glycerol or dimethylsulphoxide together with phosphatidylcholine (lecithin) or egg yolk. There could also be the combination of sucrose, $\mathrm{KHCO}_{3}$, reduced glutathione, dimethylsulphoxide and egg yolk. These diluents protect the cell membranes from physical damage by the passage through them of ice crystals as they form. An extender mimics the mineral composition of seminal plasma and also consists of some ionic components (Holtz 1993; Andrzej and Konrad, 1996). A saline solution $(\mathrm{NaCl})$ is used as a carrier of pituitary homogenates and preservation of milt. However, freshwater fishes tolerate lower salinity because higher saline concentration would probably result in the shrinkage of the sperm cells due to osmotic effect.

\section{Incubation and hatching of eggs}

Egg incubator. A polyvinyl chloride (PVC) egg incubator jar protects the eggs from fungus growth and lethal effects of the light due to its opaque walls (Dana and Eric, 1993).

Egg hatchability and fry survival. Increased efforts to fish farming have resulted to mass production of eggs and the larvae in intensive rearing system. However, high pathogenic density has had adverse effect on hatchling development and health of cultured fish. Iodophore, buffodine treatments of the eggs of Clarias batrachus (catfish) and subsequent rinsing with $0.9 \% \mathrm{NaCl}$ solution and incubated in a closed recirculated water system using a carbon filter improved the egg hatchability and hatchlings survival.

\section{Nursery management}

Fry growth and survival. $\mathrm{CoCl}_{2}$ and vitamin $\mathrm{B}$ complex could be used as carp growth promoting agents. $\mathrm{CoCl}_{2}(1 \mathrm{mg} / \mathrm{L})$ could be used also to enhance the survival of the air breathing catfish (Heteropneustes fossilis) fry. Many Scientists were of the opinion that disinfectants $\left(\mathrm{Cl}, \mathrm{I}, \mathrm{O}_{3}, \mathrm{UV}\right)$ could aid the survival of fish larvae during start feeding, and higher growth rate but had no pronounced effect on hatching or on survival of larvae during the yolk sac stage.

Fry feed. A synthetic medium could be used to culture rotifers for fish fry. The medium could be made of $\mathrm{NaHCO}_{3}, \mathrm{CaSO}_{4} \cdot 2 \mathrm{H}_{2} \mathrm{O}, \mathrm{MgSO}_{4}$ and $\mathrm{KCl}$. However, for optimum rotifer growth, medium requires $\mathrm{pH}$ 6-8, temperature of $15-30^{\circ} \mathrm{C}$, minimum dissolved oxygen (DO) level of $1.2 \mathrm{mg} \backslash \mathrm{L}$, and free of $\mathrm{NH}_{3}$, which could inhibit rotifer reproduction.

Among the several methods developed to measure feed intake in fish, radioactive tracers had been the most advantageous since the fish would not be taken out of the natural environment, or be slaughtered. The method involves radioisotope labelling of the feed and subsequent activity measurements on the living fish. Garcia-Riera and Hemre(1996) used ${ }^{14} \mathrm{C}$-labelled glucose to investigate organ responses to carbohydrate utilisation in Atlantic halibut (Hippoglossus hippoglossus) while Epp et al. (2002) used ${ }^{13} \mathrm{C}$-glycine, ${ }^{15} \mathrm{~N}$ glycine, ${ }^{15} \mathrm{~N}$-amino acid, and ${ }^{15} \mathrm{NH}_{4} \mathrm{Cl}$ labelled compounds to determine the necessary feed components needed for optimal growth of cultured organisms.

Fin and corneal opacity. A formalin (HCHO) treated fish (rainbow trout) had a significant better fin condition and a lower incidence of corneal opacity (David and Neil, 1996).

Reducing feed costs with acidifier. It is a well established fact in the field of aquaculture, that the use of antibiotic growth promoters as an in-feed additive for the diets of fish and shrimp may promote growth and feed conversion as well as improve survival rates. 


\section{Disease Control}

Intensive culture of fish has necessitated the surfacing of diseases of microbial aetiology in rearing and grow-out ponds. There're difficulties in identification, taxonomy, and the diagnostician's dilemma in deciding whether the presence of a pathogen is a disease incidence or a saprophytic growth on necroses or living tissues (Okaeme et al., 1991). Oral vaccines have not been successful due to the destruction of antigenic epitopes by the digestive processes. Interestingly, chemistry has made profound impression in veterinary sciences by enhancing the diagnosis of fish diseases.

\section{Algae Bloom, Weed and Insect Pest Control}

- Use of 3-7ppm $\mathrm{CuSO}_{4}$ when algae exceed $10 \times 10^{6}$ per litre of water.

- Use of $\mathrm{CaCO}_{3}$ to eliminate larval stages of insects.

\section{Bacteria Infections Control}

- Hyamine (a quaternary ammonium compound) bath of 2-3ppm for 1hour to control bacterial gill disease.

- Sulphonamides for systematic myxobacteria furunculosis

- Chlorine (0.1-0.2 $\left.\mathrm{mLL}^{-1}\right)$ for Aeromonas Salmonicida and Yersinia rucker

- $\mathrm{KMnO}_{4}\left(1-2 \mathrm{mgL}^{-1}\right)$ for Flexibacter Clumnaris

- $\mathrm{CuSO}_{4}$ (in a concentration of 1:2000 for 1hour) for Myxobacteria and off-flavours

\section{Fungal Infections Control}

- $\mathrm{KMnO}_{4}\left(10 \times 10^{3} \mathrm{ppm}\right)$ for 20 mins under aerated condition to disinfect eggs, fish, and pond. It also takes care of off-flavours in fish

- $\mathrm{AgNO}_{3}$ solution for swabbing of fish followed by pond flushing with $\mathrm{Ag}_{2} \mathrm{O}$

- Gentian violet as bath solution

- $\mathrm{NaCl}$ for fungal infections

- $\mathrm{CuSO}_{4} 5 \mathrm{ppm}$ bath, 1 hour, for egg fungus, especially Saprolegnia spp.

- Formalin 2000ppm bath, 1hour, for egg fungus

- Malachite greens (oxalate) $5 \mathrm{ppm}$ bath, 1 hour, for egg fungus

\section{Parasite Infections Control}

- $\mathrm{HCHO}$ (formalin) 250ppm for, 1 hour, external parasites

- Tin oxide $\left(\mathrm{SnO}_{2}\right) 25 \mathrm{~g} / 100 \mathrm{~kg}$ in feed over 3days for intestinal helminths

- Dylox (organophosphate compound) as an anti-parasitic

- Water filtration

- $\mathrm{KMnO}_{4} 1 \mathrm{~g} / 1$ dip 30-60seconds, 2-5ppm in ponds, for external parasites. It also detoxifies certain fish poisons.

\section{Viral Infections Control}

- Chlorine $\left(0.7-1.0 \mathrm{mgL}^{-1}\right)$ for infectious hematopoietic necrosis virus (IHNV) and infectious pancreatic necrosis virus (IPNV).

- Iodine for IHNV, IPNV, and viral haemorrhagic septicema viruses.

\section{Protozoan Infections Control}

- $\mathrm{CaCN}_{2}$ (Calcium Cyanamide) for pond disinfecting against protozoan.

- Covering of pond bottom with plastic foils to reduce the incidence of protozoa infection.

- Acetic acid (glacial) 2000ppm, 45-60seconds, for external protozoa, monogenetic trematodes.

- $\mathrm{CuSO}_{4} 100 \mathrm{ppm}$ bath 30 mins for external protozoa.

- Methylene blue 2ppm daily for external protozoa.

- $\quad \mathrm{NaCl} 10-30 \mathrm{~g} / 1$ for external protozoa infections such as Epistylis spp, Vorticella spp.

\section{FISH CULTURING IN FREE FLOWING WATER}

This involves the rearing of fish in cages in a free-flowing water body. Apart from permitting high stocking densities, the farmer has a complete control of the harvest. The system could be very effective as spawning, nursery and grow-out facilities. Materials such as woods and bamboo are needed to construct holding facilities such as cages and pens, and demand for these materials can be very large (Beveridge and Phillips, 1990), with local deforestation and destruction of ecosystems such as mangroves as a result. Some construction materials release substances into the aquatic environment (e.g. heavy metals, plastic additives). Many of these compounds 
are toxic to aquatic life, although some protection is given by their low water solubility, slow rate of leaching and dilution (Anon., 1991). Mortalities in coastal aquaculture have resulted from toxicant leaching from construction materials, and the environmental effects of these toxicants remain largely undetermined (GESAMP, 1991). In tropical aquaculture this problem is largely nonexistent since natural materials (such as wood or bamboo) are commonly used to construct cages and pens.

Aquaculture activities are being carried out with floating cage made from reinforced foams. These reinforced foams have excellent resistance to a wide range of chemicals and solvents and is compatible with water and solvent based coatings and adhesives, polyester and epoxy resin-based coatings. Rigid polyurethane foam is highly impervious to fungi and mould growth, non-fibrous, odourless and non-tainting.

The Talon-FDF floating cage shown below measures $6 \times 6$ metres in length, has a depth of 1.5 metres while the walk-way platform measures 0.6 metres. The cage is laid with four layers of nets; $1,1.5$ and 4 inches mesh size respectively while stones are used to anchor the cages below.

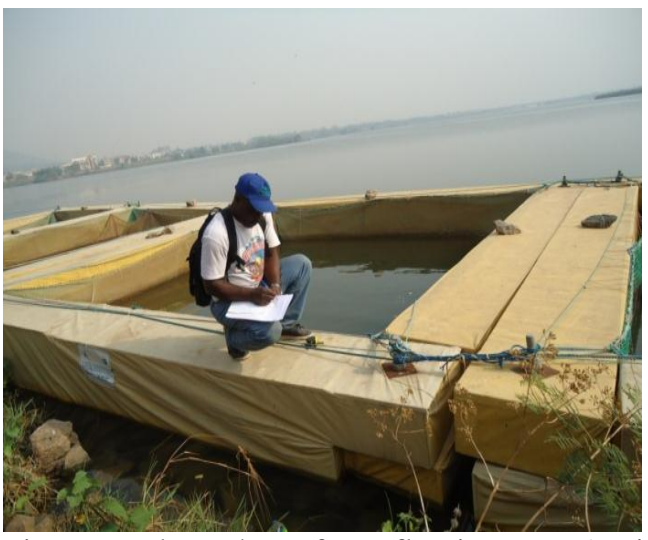

Figure : Polyurethane foam floating cage (aerial view)

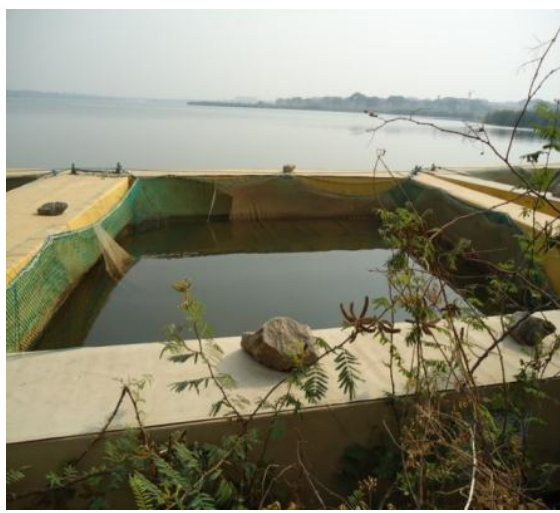

Figure : Polyurethane foam floating cage (side view)

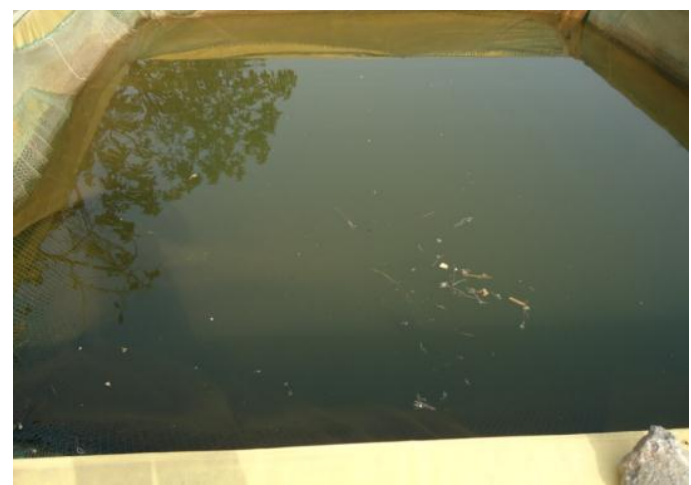

Figure : Polyurethane foam floating cage (inside view)

Within Reservoirs and other similar water bodies, fish farming is practiced in earthen ponds besides the water body. Nets are then used to screen the fish from the bird predators like ducks and other aquatic animals as shown in the figure below.

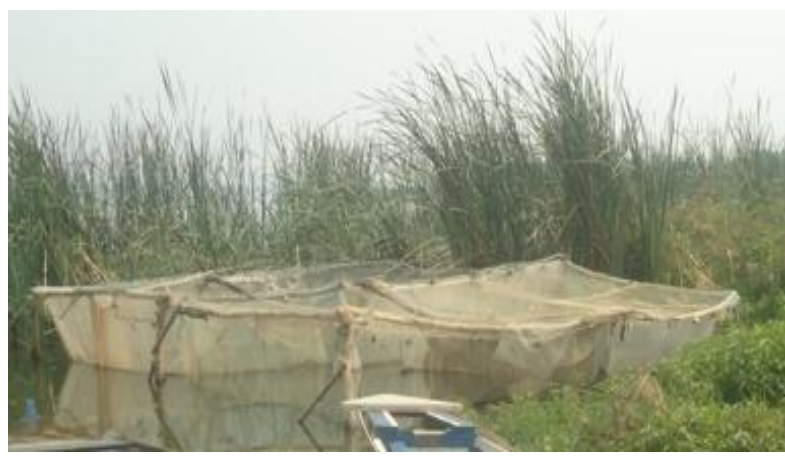

Figure : Fish farming activity on a reservoir 


\section{Main Cultured Species}

The first attempt at fish farming was in 1951 at a small experimental station in Onikan, Lagos, where different tilapias were cultured while modern pond culture started with a pilot fish farm in Panyam, Plateau State for rearing the common/mirror carp, Cyprinus carpio following the disappointing results with Tilapia culture. The success led to the establishment of fish farms at Buguma in Rivers state, Abagana in Anambra state and Agodi Garden farm in Ibadan. Although, the major species cultured include fin-fish (tilapias, catfish, and carp), catfishes of the family, Clariidae are the mostly farmed fish. Since the culture of Clarias gariepinus through hypophysation was initiated in Western Nigeria in 1973 (Elliot, 1975), the procedure has been widely practiced throughout Nigeria.

The Clarias (Clarias anguillaris and Clarias gariepinus) and Heterobranchus (Heterobranchus longifilis and Heterobranchus bidorsalis) clariid catfish, are the most important fish species cultured in Nigeria. This species has shown considerable potential as a fish suitable for use in intensive aquaculture. This fish grows rapidly, it is disease and stress resistant, high fecundity, sturdy due to the presence of arborescent air-breathing organ and highly productive in polyculture, ability to grow on a wide range of natural and low cost artificial foods and ability to withstand low oxygen and pH levels (Zheng et al., 1988; Fagbenro et al., 1993).

Sarotherodon galileaus, Tilapia zillii, Tilapia guineensis, Sarotherodon melanotheron, and Oreochromis niloticus are the cultured tilapia species. However $O$. niloticus appears to be more popular among fish farmers. It is a popular species, endemic to most part of the country and grown by many farmers (Maluwa and Costa-pierce, 1993). This species has cultural advantages characteristics such as ease of production, ready acceptance of artificial feed, fast growth, and adaptability to a wide range of environmental conditions. One of the major problems in tilapia culture is its highly prolific nature having early maturity which results in stunted populations because energy is being diverted to gonadal development instead of somatic growth (Gale et. al., 1999).

\section{Genetic Improvement}

\section{Present Status Of Research For Fish Breeding}

Current advances in aquaculture production have been achieved through the application of genetic principles which includes selective breeding, hybridization, chromosome manipulation, sex reversal, gene transfer and polyploidy (Aluko and Olufeagba, 1999). Hybridization has been used to increase growth rate, manipulate sex ratios, produce sterile animals, improve flesh quality, increase resistance, improve tolerance to environmental extremes and improve a variety of other traits that make aquatic animals production more profitable (Dunham et al., 2001). Hybridization between species can also result in offspring that are sterile or have diminished reproductive capacity. The more distantly related the two species, the greater likelihood of their hybrid being sub-viable or sterile (Chevassus, 1983). The hybrid cross between Heterobranchus and Clarias species is receiving considerable attention in Nigeria. These hybrids have been reported to show heterosis (Madu et al., 1992; Salami et al., 1993).

Tilapia is an important species for many developing countries because of its many desirable traits, such as hardiness, comparatively high resistance and suitability in a wide range of farming systems (Gupta and Acosta, 2004). A few findings (Mareau et al, 1986 and Bombatta et al, 2005 and 2006) have shown strains of tilapia in Nigeria which appear superior in growth. Essentially tilapia has a short generation time (4-6 months for O. niloticus) and therefore has the capacity to breed year round (Pullin, 1988). It implies that any genetic gain will be rapidly obtainable.

Moreau et al. (1986) studied O. niloticus from many different waters (native and introduced populations) using the growth performance index $\left(\phi^{1}\right)$. The author reported that the value of $\phi^{1}$ for Lake Kanji in Nigeria was the highest (Pullin, 1988). The possession of a high growth performance index is probably a good indicator of high growth potential in a suitable culture environment. Bombatta et al. (2005 and 2006) discovered an ecotype cichlid, 'wesafu' that is endemic to Epe lagoon, Lagos. The species is a highly priced fish in Lagos, Nigeria, for its tasty flesh and large size of over 1,500g in the wild. He opined that this fish might have a high growth potential for culture and genetic development in Nigeria.

To achieve meaningful genetic improvement, it is necessary to first assemble information on the fish through morphometric and biochemical characterization to facilitate tangible genetic improvement programme. Genetic improvement of tilapia in Nigeria is facing a major setback due to lack of fish genetic research facilities. The preparatory steps of gene isolation and construction of vectors that carries the gene is costly and requires laboratory with specialized skills (Aluko and Olufeagba, 2000).

\section{Genetic Management}

Naturally, there is genetic variability within species population. By contrast, farmed species have been selectively bred and have a low genetic variability. Unfortunately, farm-raised species have frequently escaped into the wild in vast numbers. Here they can compete with wild species for food and space putting pressure on 
wild populations. Moreover, they can interbreed with wild fish. This is problematic because of their genetic differences. Their lower genetic variability can lead to loss of unique gene pools in offspring, thereby potentially reducing their long-term adaptability to the environment. From literature, the offspring of wild species crossed with farmed species have been shown to be less fit than their parents (Naylor et al., 2005). This demonstrates how interbreeding could drive vulnerable species populations to extinction. It is therefore of great concern that significant numbers of escaped farm species are surviving long enough to breed in the wild (Hindar and Diserud, 2007). Continuing escapes may mean that the original genetic profile of the population will not reassert itself (Goldburg et al., 2001). Species escapees arise routinely due to poorly maintained or damage culture ponds.

Because farmed species may be reproductively inferior to wild species, their chances of survival in the wild may be poor. If they bred, natural selection should terminate their maladapted domestic traits. However, the sheer numbers of escaped fish, together with depleted wild species populations may mean that natural populations may be dwarfed by the escapees such that inter-breeding could lead to reduced fitness in a population and increase mortality of offspring (Scottish Executive Central Research Unit, 2002). There is also the potential for direct competition for food and habitat.

\section{Captive bred brood stock}

When a species is released into an environment where is it not native, it may reproduce successfully and have negative consequences on native species. Pérez et al. (2003), notes that the introduction of alien species into new environments, as a consequence of human activities, contributes to an irreversible and devastating impact to natural ecosystems. Tilapia have escaped from sites where they are cultured into the environment, invaded new habitats, and have become a widely distributed exotic species around the world. About $98 \%$ of farmed tilapia is now cultivated outside of its native habitat. Escapee fish are an inevitable consequence of culture in open systems of aquaculture such as cages/nets. Even closed ponds, tanks and raceways may allow fish to escape to waterways in storm conditions. Once in a non-native environment, tilapia threatens native fish by feeding on their juveniles as well as on plants that are habitat refuges for juveniles. Because tilapia are able to invade and adapt to non-native habitats, experts strongly suggest that non-native species should not be farmed in new or pristine areas because of the likelihood of escapes occurring.

\section{Wild caught brood stock}

Aquaculture of many species in the marine environment relies on juvenile fish or shellfish being caught from the wild to supply stock rather than using hatcheries to rear them. In some cases the collection of wild juveniles has led to their overexploitation. In addition, the practice may also result in the capture of juveniles of numerous other species which are discarded and die. Globally, it has been estimated that 65-75\% of all shrimp juveniles (known as post larvae) used by shrimp farms are produced in hatcheries, but shrimp farms in many areas still rely on juveniles caught from the wild. Natural stocks of shrimp are now overexploited as a result of juvenile collection. Islam et al. (2004) noted that the collection of shrimp fry not only posed serious impacts on regional biodiversity and aquatic community structure through such indiscriminate discard of juveniles but also by reducing the availability of food to other species in the food web such as aquatic birds and reptiles.

\section{Wild caught seed}

Aquaculture of some species relies on juvenile fish or shellfish being caught from the wild to supply stock, rather than using hatcheries to rear them. Shrimp farms in many areas rely on wild-caught juveniles. This has led to overexploitation and shortages of wild stocks. Furthermore, capture of shrimp juveniles also leads to the by-catch of juveniles of numerous other species which are killed in the process.

\section{Breeding and genetic improvement}

\section{Research Issues/Needs}

Aquaculture has the unique opportunity and responsibility to conserve natural (wild) populations while maintaining desirable production traits as disease resistance, fast and efficient growth, increased product yield, and lower input costs. Therefore, to support the growth of aquatic food consumption, domestication and genetic improvement of the cultivated species is a critical R\&D need. The R\&D should specifically take into consideration the following.

Maintaining and improving culture performance

- Strain selection (up to $60 \%$ difference best-worst)

- Harvesting genetic variation at the beginning of domestication

- Managing genetic variation during and after domestication. Ultimately exploiting genetic variation through selective breeding and other genetics based technologies.

Managing environmental impact (genetic pollution) 
- The potential impact of translocations and genetic changes during domestication on natural genetic diversity

- Genetic technologies to monitor and minimize impact.

As genetic changes are made in cultured populations, the nature and likelihood of interactions of domesticated animals farmed in close proximity to wild populations must be understood in order to minimize potentially adverse impacts. Aquaculture faces the dilemma of domesticating and enhancing the agronomic traits of aquatic animals for commercial production while learning best science-based practices to successfully integrate commercial interests with protective measures for natural populations. Efforts for stock restoration and recovery of imperiled species and stocking for recreation programs should strive to minimize genetic impacts on wild stocks by ensuring that genetically appropriate animals are released into native waters. There could be opportunities for commercial companies to raise aquatic species for public restoration and recreation purposes, in addition to products for commercial markets.

\section{Health management (effectively combat emerging diseases)}

Disease accounts for significant economic and ecological losses across the aquaculture sector. It is essential to control endemic, emerging and catastrophic infectious diseases that cause commercial and restoration loss of aquatic animal production and restricts commerce and movement of live aquatic animals due to the potential spread of pathogens and parasites that cause disease. While progress has been made in combating certain diseases through the use of vaccines and a limited number of approved drugs, significant losses still occur. The diversity of cultured aquatic species and associated pathogens and parasites is a significant challenge. There is great demand to improve the survival, growth, vigour, and well-being of cultivated stocks through improved technologies and practices. For example, a critical need exists to develop validated techniques for early and rapid detection of many diseases in order to prevent outbreaks and facilitate safe and timely commerce for the growth and competitiveness of aquaculture.

Research is needed to improve the characterization of causative agents of disease, their diversity, and basic epidemiological traits such as host and geographical range. Further, understanding of host immunity is needed in order to develop effective immune-biologics, drugs, and pesticides that offer broad protection and improve mass delivery systems for these agents. Molecular tools allow new and comprehensive ways to examine host immunity and disease resistance and aid in the production of vaccines and development of specific pathogenresistant brood stocks. Important targets for aquaculture animal health-related science and technology are to

- Increase the understanding of disease transmission dynamics, including carrier states, pathogen and parasite movements, and environmentally permissive factors

- Advance the understanding of the interactions between cultivated aquatic species and natural populations from an aquatic animal health perspective

- Expand and standardize biosecurity practices within culture systems to reduce the spread of disease and optimize efficient disinfection.

- Development of molecular probe for early detection and a rapid respond of viral diseases

- Cost-effective method of controlling certain infectious diseases

- Development of Probiotic and Vaccine (No antibiotic use)

- Development of standards health management

\section{Feed development (quality, safe feeds and efficient)}

Feed costs are approximately 40 to 70 percent of the variable cost of finfish and shrimp culture. Therefore, if the culture of finfish and shellfish is to increase worldwide, sustainably produced or derived alternatives to fish meal and fish oil must be found and feed ingredients need to be used more efficiently. A global challenge is to identify novel feed ingredients and develop nutritionally complete diets that support optimal performance and animal health. Prepared feeds are the main source of essential nutrients necessary for optimal growth, reproduction and health in commercially produced aquatic animals. Care must be taken to ensure that feeds do not become a source of compounds that adversely affect the health and performance of the cultured aquatic animals or human health when the animals are consumed or have unacceptable impacts on the effluent. Therefore, research should focus on:

- Developing appropriate feed substitute/supplements for fish meal and live feed for hatchery produced fry/juvenile/Grow-out

- Developing species-specific Brood stock diets that allow complete domestication and maximal reproductive and larval quality

- Better understanding of larval nutritional requirements, in order to develop suitable compound diets, which will further reduce the need for live food (Artemia). 


\section{Environmental management}

The demand for sustainable practices that minimize harm to the environment, native species, or the potential for future production resonates globally in all agricultural production sectors, including aquaculture. Aquaculture is broad-based, producing animals and plants for food, recreation, bio-energy, and protection and recovery of threatened and endangered species and habitats. Successful aquaculture depends on ecosystem services such as the availability of clean water and nutrient cycling to process or reuse wastes and co-products. In addition, aquaculture production can have a variety of effects on the environment, depending on species, production system, and location. Aquaculture's environmental performance can be improved through the efficient use of resources, public awareness of environmental issues, application of science-based best management practices (BMPs), technological innovation, knowledge about proper siting of facilities, and evolving aquaculture-specific environmental regulations.

\section{Holding systems development}

The current production systems for aquaculture include pond-based systems (e.g., catfish production); raceway systems, near-shore and offshore net-pens and cages, intertidal, off-bottom, and long-line coastal shellfish production; freshwater and marine algae production systems; and recirculation systems. There are significant opportunities to improve the performance and productivity of aquaculture production systems through advanced innovative engineering and new technologies. There is significant potential to adapt technologies and engineering solutions that at present are commercially employed in other sectors of the economy, such as municipal wastewater treatment, medicine, information technology, and energy, and to develop new system-specific technologies to aquaculture systems. Concerns related to global climate change, energy costs, and competition for resources underscore the need for technologies that support a sustainable industry by continually reducing costs while conserving natural resources and the environment.

\section{OPPORTUNITIES}

To identifying opportunities, is useful to see six general development trends of aquaculture in Nigeria:

- Continuing in/ex-tensification of aquaculture production

- Continuing diversification of species use

- Continuing diversification of production system and practices

- Increasing influence of markets, trade and consumers

- Enhancing regulation and improving governance

- Increasing attention on better management practices

In support of the above trends four areas of opportunities have been identified:

\section{Application of innovative capacity enhancement program}

Efficient, effective aquaculture production systems reduce inputs, operating costs, and wastes and create optimal conditions for animal growth, adaptability, and reproduction. Defining optimal conditions requires a comprehensive understanding of the physiology of early development, growth, stress response, and reproduction. Feeding for maintenance and growth is the most economically demanding input cost in animal production. Achieving the desired partitioning of nutrients into the competing systems of muscle development, digestive metabolism, health maintenance, and reproductive development is critical for improving productivity and reducing waste. Stressors caused by social, nutritional, and environmental factors and their interactions must be understood in order to limit adverse impacts on animal well-being that lead to poor health, sub-optimal growth and production efficiency, poor product quality, and excess environmental waste.

\section{Search for new technologies}

Aquaculture is dependent on progressive science and technological innovation to be competitive in world seafood markets, sustainable in development, and compatible with evolving social expectations. Productive aquaculture will require building a next generation of human capacity in diverse scientific fields to find solutions to scientific, economic, social, and management needs of aquaculture systems, natural resources, and 21 st century communities. Public education and understanding of new areas of science, contemporary issues, and performance of diverse aquaculture systems create a scientifically literate population leading to sound policy-making. Science-based information, integrated with new information delivery systems, offers new outreach opportunities to the public and the aquaculture community.

Most support for aquaculture R\&D originates from Federal sources. Encouraging private sector involvement through cooperative and collaborative research ensures the relevance of research investments. Technology transfer can be facilitated by collaborative partnerships with the commercial and non-commercial aquaculture community through cooperative R\&D agreements. 
Research and extension scientists, private for profit and non-profit businesses, professional societies, and industry associations all share a need to exchange information. International scientific partnerships and global communications can also accelerate technology development. Innovative approaches and new partnerships must optimize public benefits by solving critical problems and focus on strategic regional and national goals. New public policy choices and consumer preferences also raise new technology questions and drive the direction of future educational needs. Long-term development and sustainability of aquaculture will be determined, in part, by effectively connecting science, industry, and society, using innovations in education and technology transfer along with efficient communications amidst the dynamic changes in technology advancements and global competitiveness.

\section{Development of new aquatic products, markets and integration into eco-tourism sector}

Aquaculture food products contribute scientifically proven nutrition and health benefits to consumers. Therefore aquaculture can expand fish populations to further contribute to domestic fisheries. Increased consumption of farmed and wild aquaculture food products supports national priorities to reduce obesity, early childhood diabetes, and the risk of chronic disease related to food consumption and improves cognitive and cardiovascular function. There is increasing scientific evidence from human nutrition and medical research on the healthful benefits of aquatic food consumption.

\section{Development of new financial product}

As interest in commercial aquaculture production and wild species enhancement and restoration through aquaculture has increased, so too has debate about the potential economic and social effects of aquaculture. In addition, the economic viability of domestic aquaculture continues to be constrained by regulatory, environmental, economic, social, market, industry, and technological factors. Economic and social challenges can include complicated and uncertain regulatory processes, market competition affecting the prices domestic farmers and fishermen receive for their products, competition with other users of aquatic resources, and impacts to diverse cultural traditions and values.

Global market forces, for example, create economic and social pressures. The economic and social issues related to both public and private sector aquaculture goals often coincide because the species produced overlap and there is a shared need for the technologies to improve production while reducing costs. The economic and social value of aquaculture for enhancement and restoration and the links among commercial, enhancement, and restoration aquaculture need to be better understood. For example, State, Federal, non-profit and commercial hatcheries produce fish and shellfish for release to enhance commercial fisheries, supply recreational species, restore endangered, threatened, or imperiled species, rehabilitate habitat (e.g., aquatic vegetation); and mitigate for public fisheries lost as a result of water projects. These hatcheries create substantial economic value (commercial and recreational fisheries and related industries) or generate monetary and nonmonetary benefits of species and habitat restoration.

\section{CURRENT PRIORITY}

Fisheries are wild and domesticated renewable resource. Therefore to ensure longevity and prosperity, specific policies to keep the nation's natural resources available over very long-term should be a high priority. The collapse of many marine fisheries and the explosion of freshwater aquaculture have lifted the importance and precarious nature of aquatic biodiversity. Much of the impetus for this awareness has come from fishing communities whose way of life is changing radically as aquatic biodiversity is lost. These communities need to be key participants in development research on aquatic biodiversity. However, it is important to realize that, while communities rely on aquatic resources for their livelihoods their appreciation of the importance of biodiversity may be very low. Nevertheless, local fishing communities often have traditional knowledge of great value for management. Community leverage in management negotiations is much improved by knowing distribution, occurrence and status of their local species. Communities can also become participants in biological studies needed to improve management of stocks. Local and indigenous groups can be pivotal in valuing and maintaining aquatic biodiversity.

Naturally, communities take interest in responsible management once they are aware of the consequences of losing their livelihoods. Small-scale fisheries are a powerful inducement for conservation and sustainable use of aquatic biodiversity. Especially in freshwater habitats, fishing communities may be the best advocates for sustainable use. Their advocacy can be multiplied by giving them the tools to negotiate more effectively with the other sectors whose influence on habitat is likely more detrimental to aquatic biodiversity than is fishing. These tools are technical (for example, better knowledge of catch and effort) and socio-political (for example, negotiating skills). 
Inland water fisheries are mostly small-scale and play a larger role in supporting communities in developing countries than do marine fisheries. However, inland fisheries are poorly documented, and detailed knowledge of freshwater species is still concentrated in academic institutions. Increased investments need to be made in identifying and managing freshwater aquatic biodiversity in developing countries. Special attention should be paid to tropical floodplain fisheries, including collection of better harvest statistics (which can be used to gauge the health of fisheries and biodiversity).

Development investments should be made in collective action to increase local participation in fisheries management. However, there should be a clear understanding of boundaries between the biological and social sciences. First, biologists must understand their own limitations in working with communities, and thus respect the role of social science in encouraging those communities to help biologists gather information on the fisheries; and, just as importantly, their role in empowering communities to negotiate with the rest of society. Social scientists must in turn recognize the importance of good scientific understanding of fish populations and their response to outside pressures, and the limited interest of fishing communities in becoming fish biologists or managers.

Aquatic biodiversity research are characterized by a very high requirement for multi-stakeholder input (because of the multiple impacts on the resource), and participatory management of local fisheries is a major theme of most fisheries symposia today.

\section{The need for linkages and alliances}

Because aquatic ecosystems are affected by so many human actions in addition to fishing, crosssectoral linkages should be built into all aquatic development research, either explicitly, through inclusion of other sectors, or through promoting local awareness of the project and its issues. Ideally, a commitment to crosssectoral communication will require a good knowledge of the other actors involved globally in issues affecting aquatic resources since progress made in an area is dependent on progress made in the others. Programs to protect native species can help preserve genetic resilience in the face of invasions of alien species, whether accidental or introduced for aquaculture. Access to information can help managers make informed decisions: on reform in governance, new methods of pollution control, benefit-sharing, identifying protected areas, preserving mangroves and wetlands. Aquaculture may involve the building of roads into remote coastal communities and the construction of cooling facilities, and such improved infrastructure can help those same communities export native fish that currently go to waste on the beaches during peak harvest times. Coastal and Marine Management can protect these mangroves from erosion and pollution, or from pressure placed on fragile ecosystems by uncontrolled tourism or unregulated aquaculture.

Linkages and governance affect how genetic diversity can be preserved and used, and they ensure sustainability of project results. Participatory management depends on forging linkages and alliances. Investing in projects and programs that promote the building of inter-sectoral linkages and the development of systems of governance allows community participation in aquatic resource management. Finding ways to bring together technical experts, managers, communities, indigenous people and representatives of other sectors that affect aquatic biodiversity should be a priority.

\section{References}

[1]. Aluko, P. O. and Olufeagba, S. O. (1999). Genetics and food security in Nigeria in the 21st century. Genetically modified fishes; risk and prospects. P.205-206. Genetic Society of Nigeria Annual Conference.

[2]. Aluko, P. O and Olufeagba, S. O (2000).Genetically modified fish: Risks and Prospects. Genetic and food security in Nigeria, 205208.

[3]. Andrzej, C. and Konrad, D. (1996) Effect of a Sucrose-DMSO Extender Supplemented with Pentoxifylline or Blood plasma on Fertilising Ability of Cryo-preserved Rainbow Trout Spermatozoa. The Progressive Fish-Culturist 58:143-145.

[4]. Bombatta, H. A.; Ajepe, R. G. and Hammed, A. M. (2006).Food and Feeding habit of an ecotype cichlid "'wesafu'" from Epe Lagoon, Lagos, Nigeria. World Aquaculture 36 no.1.

[5]. Bombatta, H. A.; Ajepe, R. G.; Hammed, A. M. and Jimoh, A. A. (2005).Characterization of an ecotype cichlid commonly referred to as 'wesafu' endemic to Epe Lagoon Lagos, Nigeria. World aquaculture 36 (4).

[6]. Chevassus, B. (1983). Hybridization in fishes. Aquaculture 33:245-262.

[7]. Dana, D. and Eric, J. W. (1993) Polyvinyl Chlorine (PVC) Egg Incubation Jar. The Progressive Fish-Culturist 55:207-209

[8]. David, J. S. and Neil, M. (1996) Effects of Intermittent Exposure to Therapeutic Levels of Formalin growth characteristics and body condition of juvenile rainbow trout. Journal of Aquatic Animal Health 8(1):58-63.

[9]. Dunham, R. A.; Majumdar, K.; Hallerman., E. and Main G. (2001). Review of the status of aquaculture genetics. In K.R.P. Subasinghe, P. Buemo, M. J. Philipa; C. Haugh; S. E. and J. R. Arhur (eds). Aquaculture in the third millennium. Proceedings of the conference on Aquaculture in the third millennium, Bangkok, Thailand, 20-25 February, 137-186. NACA, Bangkok and FAO, Rome.

[10]. Elliot, O. O. (1975): Biological observation of some species used for aquaculture in Nigeria.

[11]. Epp, M. A.; Ziemann, D. A. and Schell, C. (2002). Carbon and Nitrogen dynamics in zero-water exchange shrimp culture as indicated by stable isotope tracers. Journal of Aquaculture Research 33(11and12):839

[12]. Fagbenro, O. A., Adedire, C.O., Owoseni E. A. and Ayotunde E. O. (1993). Studies on the biology and Aquacuclture potential of feral catfish; Heterobranchus bidorsalis (Geoffrey St Hillaire 1904). Tropical zoology 6: 67-79. 
[13]. Gale, W. L.; Martin, S. F.; Michael, L.; Contretras-Sanchez, W. M and Scherck, C. B. (1999). Masuilinization of Nile tilapia (Oreochromics niloticus) by immersion in androgens. Aquaculture 178: $349-357$.

[14]. Garcia-Riera, M. P. and Hemre, G-I (1996). Organ responses to ${ }^{14} \mathrm{C}$-glucose injection in Atlantic halibut, Hippoglossus hippoglussus(L), accumulated to diet of varying carbohydrate content. Journal of Aquaculture Research 27(8):565.

[15]. Goldburg, R. J.; Elliot, M. S. and Naylor, R. L. (2001). Marine aquaculture in the United States. Environmental impacts and policy options. Pew Oceans Commission, Philadelphia, PA, USA. 44 pp.

[16]. Hindar, K. and Diserud, O. (2007). Sắrbarhetsvurdering av ville laksebestander overfor rømt oppdrettslaks. NINA Rapport 244 (Norsk Institutt for Naturforskning). $50 \mathrm{pp}$.

[17]. Islam, M. S.; Wahad, M. A and Tanaka, M. (2004). Seed supply for coastal brackish water shrimp farming: environmental impacts and sustainability. Marine Pollution Bulletin 48: 7-11.

[18]. Madu, C. T.; Mohammed, S.; Mezie, A.; Isa, J. and Ita, E. O.(1992). Comparative growth, survival and morphometric characteristics of Clarias anguillaris, Heterobranchus bidorsalis and their hybrid fingerlings. Annual Report of the National Institute for Freshwater Fisheries Research, New Bussa, Nigeria. 7pp.

[19]. Maluwa, O. A and Costa- Pierce B. A. (1993). Effect of broodstock density on Oreochromics chiranus fry production in hapas. Journal of Applied Aqualculture 2:63 - 74 .

[20]. Mareau, J., Bambino,C and Paley D. (1986).Indices of overall growth performance of 100 Tilapia (Cichlid) population , p 201-206 . In J.L Mclean, L.B Sizon and L V Hisllos (eds). The First Asian Fisheries Forum. Asian Fisheries Society, Manila, Philippines.

[21]. Naylor, R. and Burke, M. (2005). Aquaculture and ocean resources: raising tigers of the sea. Annu. Rev. Environ. Resour. 30: 185218.

[22]. Okaeme, A. N.; Ibiwoye, T. I. I. ; Okojie, P. U. A.; Agbontale, J. J.; Isa, U. and Woru, D. (1991) Aquatic Phycomcetes of Lake Kainji and Fish Culture Facilities of Lake Kainji Areas. NIFFR Annual Report 1991, p14.

[23]. Pérez, J. E.; Alfonsi, C.; Nirchio, M.; Muñon, C. and Gómez, J. A. (2003). The introduction of exotic species in aquaculture: a solution or part of the problem? Interciencia 28 (4): 234-238.

[24]. Pullin R. S. V. (1988). Tilapia Genetic Resources for Aquaculture: Proceedings of the workshop on Tilapia Genetic Resources for Aquaculture, 23-24 March, 1987, Bangkok, ICLARM, Manila, Philippines.

[25]. Salami, A. A.; Fagbenro, O. A. and Sydenham, D. H. J.(1993). The production and growth of clariid catifish hybrids in concrete tanks. The Israeli Journal of Aquaculture-Bamidgeh 45(1): 18-25.

[26]. Scottish Executive Central Research Unit (2002). Review and synthesis of the environmental impacts of aquaculture. The Scottish Association for Marine Science and Napier University. Scottish Executive Central Research Unit. The Stationery Office, Edinburgh, UK. $71 \mathrm{pp}$.

[27]. Zelennikov, O. V. (1996) Effect of Acidification on Oogenesis of Rainbow Trout during Sex Differentiation. Journal of Fish Biology 50(1):18-20.

[28]. Zheng Wembians, Pan Jionghus and Liu Wensheg (1980). Review; culture of catfish in China. Aquaculture 75, 35-44. 